\title{
Gestation length in red deer: genetically determined or environmentally controlled?
}

\author{
GW Asher \\ AgResearch, Ltd, Invermay Agricultural Centre, Private Bag 50034, Mosgiel, New Zealand
}

The red deer (Cervus elaphus) of European origin (e.g. subspecies scoticus, hispanicus, hippelaphus) is a medium sized (100-150kg mature hind weight) ruminant that exhibits highly seasonally patterns of autumn conceptions and summer births. Historic data indicate average ( \pm s.d.) gestation length of 233-234 ( $\pm 2-4)$ days. Recently, however, there has been growing awareness that there is considerably greater variation in gestation length than earlier indicated and that there is a significant element of environmental, and possibly even social, control over the duration of pregnancy in this species. Imposition of variable levels of nutrition over late pregnancy of red deer hinds has been observed to influence fetal growth trajectory and gestation length, with no apparent effect on birth weight. This supports a hypothesis that under conditions of modest feed imbalance, variation in gestation length compensates for variation in fetal growth trajectory to ensure optimisation of birth weight. More recent studies on primiparous ( 24 month old) red deer hinds have identified surprisingly large variation in gestation length (193-263 days) compared with adult hinds (228-243 days), with earlier conceiving individuals within the primiparous cohort expressing significantly longer gestation than the later conceiving hinds, resulting in a higher level of calving synchrony than expected from known conception dates. This introduces an intriguing hypothesis of social indicative effects on parturition timing to promote within-cohort birth synchrony. Collectively, these data debunk the commonly held notion that gestation length of red deer is genetically fixed within strict limits. A review of the literature points to this as possibly a common phenomenon across a range of non-domesticated ruminant species but this conclusion is not supported by numerous conflicting studies on domestic sheep and cattle.

\section{Introduction}

A species-specific gestation period (that is, interval from fertilisation to birth) is a profound feature of mammalian reproductive cycles. The trophoblast has a finite lifespan, serving as a fundamental clock in the timing of events which terminate pregnancy (Holm 1966). The metabolism of the conceptus however determines the absolute timing of gestation length, with the most important fetal contribution to the initiation of parturition (in ruminants at least) being 
the secretion of glucocorticoids from the fetal adrenal glands (Liggins 1979). As a general rule across species, gestation length is positively correlated with adult body size although seasonal imperatives for relatively longer mating-to-birth intervals for some species may extend apparent gestation length though delayed development processes such as "delayed implantation/ embryonic diapause" (for example, roe deer, Capreolus capreolus: Aitken et al. 1973).

There is a general underlying acceptance that gestation length for any given species is genetically programmed and relatively robust in the face of variations in environmental conditions. Recognition is given to the influence of fetal genotype as being the single most important determinant of gestation length; as well as determining interspecific differences in gestation length it also accounts for subspecies and breed differences (Kenneth \& Ritchie 1953; Racey 1981). Indeed, this has been demonstrated for the red deer species (Cervus elaphus) in which there is considerable subspecies variation in observed mating-birth intervals ranging from 233 days for C. e. scoticus (Scottish red deer) (Guinness et al. 1971) to 247 days for C. e. nelsoni, roosevelti, manitobensis (North American Wapiti subspecies) (Haigh 2001). Red deer hinds gestating $\mathrm{F} 1$ crossbred red $x$ Wapiti fetuses show a mating-calving interval of $\sim 239$ days (Asher et al, 2005a). Similarly, although Père David's deer (Elaphurus davidianus), with a reported gestation length of 280 + days, are classified within a different genus, hybridisation with red deer hinds can result in fertile offspring. Red deer hinds gestating $\mathrm{F} 1$ hybrid red $\mathrm{x}$ Père David fetuses exhibit a wide range in mating-calving intervals from 262 to 274 days (Asher et al. 1988).

Environmental modifiers of gestation length have been documented and include photoperiod, stress, nutrition and temperature, to name a few (Racey 1981). However, such modifiers have exerted relatively minor effects $(1-2 \%$ change in established species-specific gestation length). In the case of medium-sized ruminants (that is, $50-350 \mathrm{~kg}$ mature female weight), species-specific gestation lengths generally range between 150-300 days, with a co-efficient of variation of $1-2 \%$.

Perhaps the most notable departure from rigorous genetic control of gestation length has been described for members of the Camelidae family. Alpacas (Lama pacos), for example, not only control the parturition process to ensure births occur during daylight hours and not during inclement weather (Reiner \& Bryant 1983), but also exhibit considerable seasonal variation in gestation length (Knight et al. 1995; Davis et al. 1997). A comparison of pregnancies from spring and autumn matings showed that gestation lengths were 10-12 days longer with spring conceptions. For each day later in spring that a female was mated there was an increase in gestation length of 0.11 days (Davis et al. 1997). A similar phenomenon has been noted in the dromedary camel (Camelus dromedaries) (Elias et al. 1991). Such variations in gestation length are greater than the natural variance observed within cohorts and clearly indicates unspecified environmental modifiers.

\section{Gestation Length in Red Deer}

The red deer, of temperate European origin (for example, subspecies scoticus, hispanicus, hippelaphus), is a medium sized ( $100-150 \mathrm{~kg}$ mature hind weight) ruminant that exhibits highly seasonal patterns of autumn conceptions and summer births (Lincoln and Short 1980). In most natural environments in which red deer exist, there are harsh penalties on calf survival if births occur late in the proscribed season due to the inability of late-born calves to attain sufficient body mass to cope with their first winter (Albon et al. 1983). Thus, selection pressure for optimum calving seasonality has been a major feature of red deer evolution. While numerous studies have investigated seasonality drivers around conception, little attention has been given 
to further effects around the precise timing of parturition due to the assumption that gestation length is genetically-fixed within strict limits. Numerous data sources indicate an average ( \pm s.d.) gestation length of 233-234 $( \pm 2-4)$ days (for example: Guinness et al. 1971; Krzywinski \& Jaczewski 1978; Kelly et al. 1982; Asher et al. 1988). Recently, however, there has been growing awareness that there is considerably greater variation in gestation length than earlier indicated and that there is a significant element of environmental, and possibly even social, control over the duration of pregnancy. The first indications of a greater variation in the gestation lengths for red deer than expected were from anecdotal accounts related to artificial insemination (AI) to artificially synchronised oestrus. Given a red deer oestrous cycle length of 18-19 days (Guinness et al. 1971; Asher et al. 2000), it is in theory a simple process to determine which hinds conceived to $\mathrm{Al}$ (to red deer sires) and which hinds returned to oestrus 18-19 days later based on calving date relative to Al data; those hinds with apparent gestation lengths $>240$ days, were likely to have had return-service conceptions. However, there were several apparently ambiguous situations in which DNA genotyping clearly identified calves from such late parturitions as being the result of conceptions to the Al semen. This indicated a wider variance for red deer gestation length than previously thought. However, the mechanisms behind the variation were obscure.

More recently, Asher et al. (2005b) observed a marked effect of level of dam nutrition between days 150 and 220 of pregnancy on fetal growth and gestation length. In the study, conducted on individually penned red deer hinds, (C.e. scoticus x hippelaphus) mated to similar genotype stags, a range of nutritional allowances from ad-libitum intake to a $50 \%$ restriction was offered. There were no discernable effects on calf (sex corrected) birth weights but dams expressed unexpectedly wide variation (range $=27$ days) in gestation length, with low-nutrition hinds exhibiting longer gestations ( $>240$ days) than high nutrition hinds ( $<230$ days). Furthermore gestation length was negatively correlated with change in hind live weight (reflecting nutritional level) between days 150 and 220 of pregnancy. It was concluded from this study that variation in nutrition to hinds during the last trimester may strongly influence fetal development but, under conditions of feed imbalance, variation in gestation length compensates to ensure optimisation of birth weight (and maximise calf survival) (Asher et al. 2005b). Such a compensatory mechanism would seem to be driven by a model of fetal induction of parturition dependent on attainment of specific size or stage of development being influenced by fetal growth trajectory (Liggins 1979).

More recently, Garcia et al. (2006) observed that Spanish red deer hinds (C.e. hispanicus) induced to conceive 6-8 weeks before the natural breeding season exhibited extended gestation lengths by 8 - 10 days compared with control hinds, but there were no discernable effects on birth weight. While they postulated that optimisation of birth date was the principal driver of the effect, their study was confounded by lower live weight gains over pregnancy in the earlyconceiving hinds. Their data, therefore, show some support for a nutritional-fetal growth influence on gestation length in red deer.

There are, however, some apparent contradictions to this hypothesis, not the least of which being the consistency in average gestation length and its variance in previous studies of red deer. In these cases it could be argued that such observations are based on cohorts in which individuals are subjected to similar levels of nutritional management and unlikely to include groups subjected to severe nutritional constraints (Asher etal. 2005b). More pertinently though, considerable variation in birth weight has been recorded previously for red deer populations subjected to severe variations in their nutritional environment. Most notably, Albon et al. (1983) demonstrated a significant positive correlation between mean daily temperature during late pregnancy and subsequent mean birth weight across a number of years for red deer on the 
Isle of Rhum, Scotland. From this observation they contended that differential nutritional environments across years influenced mean birth weight via fetal growth. Similarly, Thorne et al. (1976) demonstrated for North American Wapiti (C.e. nelsoni) that birth weights of calves was correlated with hind nutrition during the later half of pregnancy.

The major difference between these studies and that of Asher et al. (2005b) and Garcia et al. (2006) is the apparent severity of nutritional constraint. It is possible, based on live weight and body condition data presented, that the earlier studies of Albon et al. (1983) and Thorne et al. (1976) imposed or compared nutritional levels considerably more extreme than the late studies. Thus the compensatory hypothesis presented by Asher et al. (2005b) may apply only under conditions of moderate nutritional imbalance.

Interestingly, such compensatory mechanisms have not been demonstrated for fallow deer (Dama dama) subjected to modest levels of feed deprivation. Mulley (1989) described fetal growth retardation and low birth weight associated with a 20-30\% reduction in metabolisable energy intake in the second and third trimesters of pregnancy, with no significant effects on gestation length. However, some support for the hypothesis of compensatory control in gestation length in red deer lies with a few studies on other non-domesticated ruminants.

Verme (1965) showed that the gestation length of white-tailed deer (Odocoileus virginianus) increased by 4-6 days when feed intake was restricted during pregnancy. Similarly, analysis of the birth seasons of Alaskan moose (Alces alces gigas) indicates that the timing of births occurred earlier for hinds with the thickest rump fat during pregnancy (Keech et al. 2000). In a non-cervid example, Skinner and van Zyle (1969) found that African eland (Taurotragus oryx) in poor nutritional habitats had longer pregnancies than those in richer habitats. These examples hint at a more widespread phenomenon of environmental control of gestation length in nondomesticated ruminants. It should be noted, however, that similar nutritional studies on domesticated sheep and cattle show contradictory and smaller effects (Alexander 1956; Bewg et al. 1969; Tudor 1972; Wallace et al. 1999) demonstrating that such compensatory mechanisms are not universal.

\section{Can the social environment influence gestation length?}

A recent study on a single cohort of 78 primiparous ( 24 month old) red deer hinds, in which conception date was established by direct observation of mating and fetal age measured by ultrasonography, revealed an unexpected and surprisingly large variation in yearling gestation length (193-263 days) compared with a contemporary cohort of 80 adult hinds (228-243 days) (IC Scott \& GW Asher, unpublished data). Interestingly, the earlier conceiving individuals within the primiparous cohort expressed significantly longer gestations than the later conceiving hinds, resulting in a higher level of within-herd calving synchrony than expected from the known conception dates. There was no evidence of any live weight or body condition effects.

In the absence of any other explanatory variable, it was considered that a putative "social facilitation" effect may be operating to promote within-herd synchrony of births. This hypothesis is presently being tested under more controlled conditions that take seasonality variables into account. However, while there may be strong evolutionary drivers to promote birth synchrony within herds (for example, prey saturation), these have always been seen previously to act via selection pressure on conception synchronisation (often including a social component) and uniformity of gestation length. 


\section{Conclusions}

Collectively, these studies debunk the commonly held notion that gestation length of red deer is genetically fixed within restricted limits, and indicates environmental (and social?) modifiers acting as buffers to enhance neonate survival. Such phenomena may not be limited to red deer and have, to various degrees, been observed in other cervid and non-cervid ruminants.

\section{References}

Aitken RJ, Burton I, Hawkins J, Kerr-Wilson R, Short RV \& Steven DH 1973 Histological and ultrastructural changes in the blaslocyst and reproduclive tracl of the roe deer (Capreolus capreolus) during delayed implantation. Journal of Reproduction and Fertility 34 481-493.

Albon SD, Guinness FE \& Clutton-Brock TH 1983 The influence of climatic variation on the birth weights of red deer (Cervus elaphus). Journal of Zoology (London) 200 295-297.

Alexander G 1956 Infiluence of nutrition upon duration of gestation in sheep. Nature (London) 178 10581059.

Asher GW, Adam JL, Otway W, Bowmar P, van Reenan G, Mackintosh CG \& Dratch P 1988 Hybridisation of Père David's deer (Elaphurus davidianus) and red deer (Cervus elaphus) by artificial insemination. Journal of Zoology (London) 215 197-203.

Asher GW, O'Neill KT, Scott IC, Mockett BG \& Fisher MW 2000 Genetic influences on reproduction of female red deer (Cervus elaphus). (1) Seasonal luteal cyclicity. Animal Reproduction Science 59 43-59.

Asher GW, Scott IC, O'Neill KT \& Littlejohn RP 2005a Influence of level of nutrition during late pregnancy on reproductive productivity of red deer (2) Aduif hinds gestating wapiti $x$ red deer crossbred calves. Animal Reproduction Science 86 285-296.

Asher GW, Mulley RC, O'Neill KT, Scott IC, Jopson NB \& Littlejohn RP 2005b Influence of level of nutrition during late pregnancy on reproductive produclivity of red deer (1) Adult and primiparous hinds gestating red deer calves. Animal Reproduction $5 \mathrm{ct}$ ence 86 261-283.

Bewg WP, Plasto AW \& Daly KK 1969 Studies on reproductive performance of beef cattle in a sub-tropical environment. 1. Conception rate, length of oestrous cycle and length of gestation. Queensland Journal of Agricultural Animal Science 26 629-637.

Davis GH, Dodds KG, Moore GH \& Bruce GD 1997 Seasonal effecis on gestation length and birth weight in alpacas. Animal Reproduction Science 46297 . 303.

Elias E, Degen AA \& Kam M 1991 Effect of conception date on length of gestation in the dromedary camel (Camelus dromedaricus) in the Negev Desert. Animal Reproduction Science 25 173-177.

Garcia AJ, Landete-Castillejos T, Carrion D, Gaspar-Lopez E \& Gallego L 2006 Compensatory extension of gestation length with advance of conception in red deer (Cervus elaphus). Journal of Experimental Zoology 305A 55-61.

Guinness FE, Lincoln GA \& Short RV 1971 The reproductive cycle of the female red deer, Cervus elaphus. Journal of Reproduction and Fertility 27 427-438.

Haigh IC 2001 The gestation length of wapifi (Cervus elaphus) revisited. Animal Reproduction Science 65 89.93.

Holm LW 1966 Prolonged pregnancy. Advanced Veterinary Science 11 159-205.

Keech MA, Bowyer RT, ver Hoef IM, Boertje RD, Dale BW \& Stephenson TR 2000 Life-history consequences of maternal condition in Alaskan moose. Journal of Wildlife Management 64(2) 450-462.

Kelly RW, McNatty KP, Moore GH, Ross D \& Gibb M 1982 Plasma concentrations of LH, prolactin, oestradiol and progesterone in female red deer (Cervus elaphus) during pregnancy. Journal of Reproduction and Fertility 64 475-483.

Kenneth JH \& Ritchie GR 1953 Gestation periods, a table and bibliography. Téchnical Communications. of the Commonwealth Bureau of Animal Breeding and Genetics No 5.

Knight TW, Ridland M, Scott I, Death AF \& Wyeth TK 1995 Foetal mortality at different stages of gestation in alpacas (Lama pacos) and the associated changes in progesterone concentrations. Animal Reproduction Science 40 89-97.

Krzywinski A \& Jaczewski Z 1978 Observations on the artificial breeding of red deer. Symposium of Zoology Society (london) 43 271-287.

Liggins GC 1979 Initiation of parturition. Breeding Medical Bulletin 45 145-150.

Lincoln GA \& Short RV 1980 Seasonal breeding: nature's contraceptive. Recent Progress in Hormone Research $36 \quad 1-52$.

Mulley RC 1989 Reproduction and performance of farmed fallow deer (Dama dama). Ph.D Thesis. The University of Sydney, Australia.

Racey PA 1981 Environmental factors affecting the length of gestation in mammals. In Environmental Factors in Mammal Reproduction, pp 199-213. Eds B Cook and DF Gilmore. London: Macmillan.

Reiner R \& Bryant F 1983 A different sort of sheep. Rangelands 5(3) 106-108.

Skinner JD \& van Zyle JMH 1969 Reproductive performance of the common eland, Taurotragus oryx, in two environments. Journal of Reproduction and Fertility Supplement 6 319-322. 
Thorne ET, Dean RE \& Hepworth WG 1976 Nutrition during gestation in relation to successful reproduction in elk. Journal of Wildlife Management $\mathbf{4 0}(2)$ 330-335.

Tudor GD 1972 The effect or pre- and post-natal nutrition on the growth of beef cattle. 1. The effect of nutrifion and parity of the dam on calf birth weight. Australian lournal of Agriculture and Research 23389. 395.
Verme L) 1965 Reproduction studies on penned whitetailed deer. Journal of Wildlife Management 2974 79.

Wallace JM, Bourke DA \& Aitken RP 1999 Nutrition and foetal growth: paradoxical effects in the overnourished adolescent sheep. Journal of Reproduction and Fertility Supplement 54 385-399. 